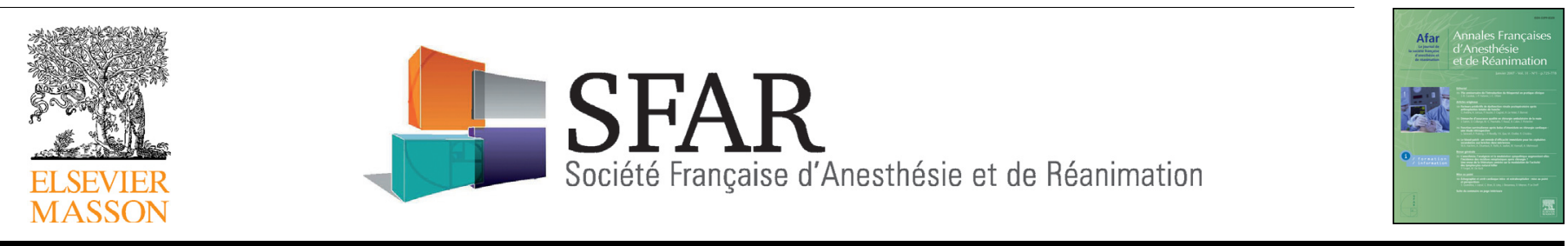

Anarlf meeting

\title{
Assessing consciousness in coma and related states using transcranial magnetic stimulation combined with electroencephalography ${ }^{\text {is }}$
}

\section{Évaluation de la conscience chez les patients en coma et en états apparentés par stimulation magnétique transcrânienne combinée à l'électroencéphalographie}

\author{
Olivia Gosseries ${ }^{\mathrm{a}, *, \mathrm{~b}, \mathrm{c}}$, Aurore Thibaut ${ }^{\mathrm{a}}$, Mélanie Boly ${ }^{\mathrm{a}, \mathrm{b}, \mathrm{d}}$, Mario Rosanova ${ }^{\mathrm{e}}$, \\ Marcello Massimini ${ }^{\mathrm{e}, \mathrm{f}}$, Steven Laureys ${ }^{\mathrm{a}}$

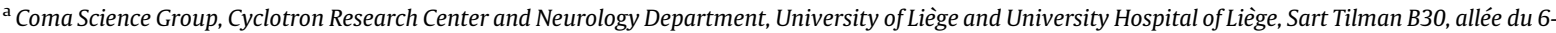 \\ Août- $n^{\circ}$ 8, 4031 Liège, Belgium \\ ${ }^{\mathrm{b}}$ Center for Sleep and Consciousness, Department of Psychiatry, University of Wisconsin, Madison, WI, USA \\ ' Postle Laboratory, Department of Psychology and Psychiatry, University of Wisconsin, Madison, WI, USA \\ ${ }^{\mathrm{d}}$ Department of Neurology, University of Wisconsin, Madison, WI, USA \\ e Department of Biomedical and Clinical Sciences "Luigi Sacco", University of Milan, Milan, Italy \\ ${ }^{\mathrm{f}}$ Istituto Di Ricovero e Cura a Carattere Scientifico, Fondazione Don Carlo Gnocchi, 20148 Milan, Italy
}

\section{A R T I C L E I N F O}

\section{Keywords:}

Disorders of consciousness

Unresponsive wakefulness syndrome

Vegetative state

Minimally conscious state

Locked-in syndrome

Transcranial magnetic stimulation

Electroencephalography

Anesthesia

Sleep

Brain stimulation

\begin{abstract}
A B S T R A C T
Thanks to advances in medical care, an increased number of patients recover from coma. However, some remain in vegetative/unresponsive wakefulness syndrome or in a minimally conscious state. Detection of awareness in severely brain-injured patients is challenging because it relies on behavioral assessments, which can be affected by motor, sensory and cognitive impairments of the patients. Other means of evaluation are needed to improve the accuracy of the diagnosis in this challenging population. We will here review the different altered states of consciousness occurring after severe brain damage, and explain the difficulties associated with behavioral assessment of consciousness. We will then describe a non-invasive technique, transcranial magnetic stimulation combined with high-density electroencephalography (TMS-EEG), which has allowed us to detect the presence or absence of consciousness in different physiological, pathological and pharmacological states. Some potential underlying mechanisms of the loss of consciousness will then be discussed. In conclusion, TMS-EEG is highly promising in identifying markers of consciousness at the individual level and might be of great value for clinicians in the assessment of consciousness.

๑) 2013 Société française d'anesthésie et de réanimation (Sfar). Published by Elsevier Masson SAS. All
\end{abstract} rights reserved.

R É S U M É

Avec les avancées récentes de la médecine, de plus en plus de patients sortent du coma. Cependant, certains restent en état végétatif/syndrome d'éveil non-répondant ou en état de conscience minimale. L'évaluation de leur niveau de conscience reste difficile notamment parce qu'elle repose sur des examens comportementaux qui peuvent être biaisés par des déficits moteurs, sensoriels et cognitifs. D'autres outils d'évaluation de la conscience sont donc nécessaires afin de préciser le diagnostic des patients sévèrement cérébrolésés. Dans cet article, nous exposerons les différents états de conscience altérée survenant à la suite d'une grave lésion cérébrale et les difficultés liées à l'évaluation du niveau de conscience au chevet des patients. Nous décrirons ensuite une technique non invasive, la stimulation magnétique transcrânienne combinée à l'électroencéphalographie à haute densité (SMT-EEG) qui permet de détecter la présence ou l'absence de conscience dans différents états physiologiques,
Troubles de la conscience

Syndrome d'éveil non-répondant

État végétatif

État de conscience minimale

Locked-in syndrome

Stimulation magnétique transcrânienne

Électroencéphalographie

Anesthésie

Sommeil

Stimulation cérébrale

\footnotetext{
French NeuroAnesthesia and Intensive Care Society Meeting, Paris, November 2013, 21st and 22nd: "The acutely brain-injured patient: consciousness and neuroethic".

* Corresponding author.

E-mail address: ogosseries@ulg.ac.be (O. Gosseries).
}

0750-7658/\$ - see front matter @ 2013 Société française d'anesthésie et de réanimation (Sfar). Published by Elsevier Masson SAS. All rights reserved. http://dx.doi.org/10.1016/j.annfar.2013.11.002 
pathologiques et pharmacologiques. Des mécanismes potentiels pouvant expliquer la perte de conscience seront ensuite discutés. Dans notre conclusion, nous exposerons les avantages de la SMTEEG et en quoi cette technique prometteuse pourrait être d'une grande utilité pour évaluer le niveau de conscience au chevet des patients.

(c) 2013 Société française d'anesthésie et de réanimation (Sfar). Publié par Elsevier Masson SAS. Tous droits réservés.

\section{Disorders of consciousness}

Since the invention of mechanical ventilation in the 1950s, many patients survive even after severe brain damage. After the comatose phase where patients lie with eyes closed (i.e., coma), some patients regain full consciousness while some progress to a state of preserved wakefulness in the absence of awareness (i.e., unresponsive wakefulness syndrome). Others show fluctuating signs of awareness but they remain unable to communicate consistently (i.e., minimally conscious state). Finally, some patients fully recover awareness but lack motor output (i.e., locked-in syndrome).

\subsection{Coma}

Coma is an acute state of non-responsiveness in which patients cannot be awakened even when intensively stimulated [1]. Patients in a coma lack sleep-wake cycles and only show some reflex behaviors [2]. The autonomous functions such as breathing and thermoregulation are reduced and global brain metabolism is significantly diminished [3]. Coma is the result of diffuse cortical or white matter damage and/or an acute lesion in the brainstem [4]. It lasts at least one hour (to be distinguished from syncope) and up to a few days. The prolonged coma also exists but is rare and can last two to five weeks (e.g., pharmacologically-induced coma).

\subsection{Unresponsive wakefulness syndrome}

This state was first named apallic syndrome [5] or coma vigil [6], and in 1972 it was termed vegetative state [7]. New terminology was proposed in 2010 - the unresponsive wakefulness syndrome (UWS) [8] - to avoid the strong negative connotation with inadvertently risking comparisons between patients and vegetables. The term "UWS" also allows a more precise description of the clinical state, referring to patients that are unable to react to stimuli in a non-reflexive way (hence unresponsive), whilst showing periods of time with eyes opened (hence wakefulness). Clinically, this state is thus defined by wakefulness without awareness, and in which patients are able to open their eyes but remain unaware of the environment and themselves [9]. They only show spontaneous or stimulus-induced reflex behaviors such as grinding teeth, moving eyes, swallowing, chewing, yawning or groaning. This state may be transitory, chronic or permanent.

Although recovery of the sleep-wake cycle is part of the criteria of UWS, recent studies have demonstrated an absence of electrophysiological characteristics of sleep in UWS [10,11]. Brain metabolism is usually diminished by 40 to $50 \%$ with impaired cortico-thalamo-cortical circuits but relatively preserved brainstem functions [12]. Brain dysfunctions are more specifically located in the frontoparietal network (including both medial and lateral networks related to self and environment respectively) and in the thalami [13]. During sensory stimulations, UWS patients usually show metabolic brain activation that remains isolated in the primary cortices $[14,15]$. Finally, top-down processes from frontal to temporal cortices have been shown to be impaired in patients in UWS when measuring the electrical activity during auditory stimulations [16].

\subsection{Minimally conscious state}

The minimally conscious state (MCS) is characterized by primary inconsistent signs of consciousness $[17,18]$. The criteria of MCS, introduced in 2002, include reproducible responses to verbal or written commands, visual pursuit, localization to pain, intelligible verbalizations, intentional communication and reaching/holding objects [18]. Adapted emotional behaviors such as smiles, laughs or tears can also be observed [18]. This clinical entity has been recently subcategorized in "minimally conscious plus" (MCS+) for patients who present high-order behavioral responses to stimuli (e.g., response to a command which involves the preservation of language) and "minimally conscious minus" (MCS-) for patients who only show low-level non-reflexive responses to stimuli (e.g., visual pursuit or localization to nociception) [19]. This classification is supported by neuroanatomical data that demonstrate better preservation of languagerelated networks in MCS+ as compared to MCS - patients [20]. The overall cerebral metabolic activity in MCS patients is usually reduced but the autonomous functions are preserved, and corticothalamo-cortical connections are partly restored [21]. The main metabolic dysfunctions appear to be located in the lateral network and in the thalami [13]. When patients recover the ability to functionally communicate or to use objects adequately, this is referred to "emergence of the minimally conscious state" (EMCS) [18].

\subsection{Locked-in syndrome}

Locked-in syndrome (LIS), also known as pseudocoma, is not a disorder of consciousness per se but can be mistaken as one. LIS is characterized by a complete paralysis of the body resulting from a lesion in the brainstem affecting the pyramidal tract, most frequently due to an ischemic pontine lesion [17]. If the lesion is only restricted to the brainstem, LIS patients have preserved sensory and cognitive functions [22]. The primary way of communication is through vertical eye movements or blinking [23]. Through the recovery of distal movements, such as the tip of a finger or head movement, chronic LIS patients are often able to communicate via a computer and to control their wheelchair. Communication has also been recently made possible by measuring electrical brain activity [24] and pupil size [25]. Finally, many chronic LIS patients report having a happy and meaningful life and the demand for euthanasia, albeit existing, is not so frequent [26].

\section{Assessment of the level of consciousness}

To date, the level of consciousness is mainly assessed at the patient's bedside by searching for response to command or nonreflexive behaviors in response to sensory stimulations. Assessing the presence or absence of consciousness of non-communicative brain-damaged patients is however difficult, as consciousness is a subjective first-person experience, and one has necessarily to make inferences about its presence based on the patient's behavior. Currently, the diagnostic decision-making process is extremely challenging leading to a diagnostic error rate up to $40 \%$ when not assessed with appropriate standardized scales [27]. The Coma Recovery Scale-Revised (CRS-R) has been shown to be the 
best scale to differentiate between UWS and MCS patients [28,29] In the acute setting, the Full Outline of UnResponsiveness (FOUR) has also been proposed as an alternative scale for the widely used Glasgow Coma Scale because it facilitates the diagnosis of LIS patients, and it includes assessment of visual pursuit (one of the first behaviors observed when a patient emerges from coma) [30].

Even with the best clinical assessment, patients might be underestimated in terms of residual awareness due to motor dysfunction, sensory deficit, impaired cognition or fluctuation of vigilance that can prevent voluntary responses [31]. Recent studies provide evidence for preserved awareness in some UWS patients [32]. For instance, using functional magnetic resonance imaging (fMRI) or electroencephalography (EEG) such patients generated appropriate brain responses, similar to those observed in healthy controls, when instructed to perform cognitive tasks (e.g., activation of the supplementary motor area when asked to imagine playing tennis) [33-35]. Despite being unresponsive at the bedside, these patients should be considered conscious and their diagnosis should be replaced. The terms "functional LIS" [19], "functional MCS" [36] and "MCS*" [37] have been recently suggested to define patients who show non-behavioral evidence of consciousness that is only measurable via neuroimaging testing.

These recent technologies using active EEG and fMRI paradigms are therefore helpful in detecting consciousness in some UWS patients but they cannot be used at the single-subject level due to a high rate of negative results. Moreover, these tools require preserved language comprehension and the active participation of the patients. The combination of single-pulse transcranial magnetic stimulation (TMS) with EEG overcomes these issues and can be employed at the bedside to assess brain function.

\section{Transcranial magnetic stimulation combined with electroencephalography}

TMS has been used for neurological and psychiatric research applications since the early 1980s. This non-invasive technique allows stimulating the cerebral cortex non-invasively by generating a brief but strong magnetic pulse through a coil applied to the surface of the scalp. The fast change in magnetic field strength induces a current flow in the tissue, which results in the activation of underlying neuronal populations [38]. TMS was first applied to the motor cortex with single-pulses, and electromyography responses were recorded from peripheral muscles [39]. Repetitive TMS has since been used to induce a sustained inhibition (i.e., $<1 \mathrm{~Hz})$ or activation $(>1 \mathrm{~Hz})$ of the neuronal population, which allowed stimulating other brain areas while observing the subsequent behavioral and cognitive changes [40]. In the last several years, TMS has been combined with high-density EEG and a neuronavigation system to directly measure the activity of the brain itself (instead of measuring muscular activity or behavioral responses induced by the TMS stimulation) (Fig. 1). In this way, single-pulses TMS induce focal neuronal discharge at the cortex surface, and an EEG measures cortical electrical responses both locally and at distant sites. This enables study of cortical excitability under the site of stimulation, and long-range cortical effective connectivity (i.e., causal interactions between distant brain areas) with good spatio-temporal resolution [41]. The neuronavigation system allows precise stimulation of a selected brain area and ensures stability of the position of the stimulation as well as reproducibility among different sessions [42,43]. Studies demonstrated that meaningful recordings could be derived without being substantially affected by TMS-induced artifact thanks to new hardware solutions, improved EEG amplifier technology, and advanced data processing techniques [44]. Using recent source modeling and statistical analyses, it is currently possible to detect

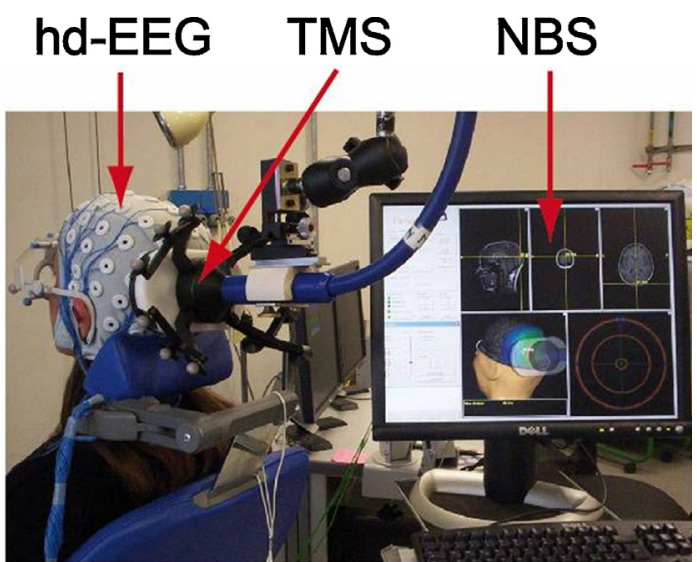

Fig. 1. Set up of the TMS-EEG technique. Hd-EEG: high-density electroencephalography; TMS: transcranial magnetic stimulation; NBS: navigated brain stimulation including the structural MRI of the subject. Taken from [42].

the effect of the focal perturbation both at distance and in time [45].

\subsection{TMS-EEG in healthy awake subjects}

Using a 60-channel TMS-compatible EEG amplifier, Massimini et al. [46] showed that during wakefulness, TMS triggers sustained long-range and complex patterns of activation. TMS induces low-amplitude wave shapes, which are associated with spatially and temporally differentiated responses (Fig. 2A) [47]. These brain responses vary depending on the site of stimulation, meaning that each cortical area tends to preserve its own natural frequency (Fig. 2B) [48]. For instance, TMS consistently evoked dominant alpha-band oscillations $(8-12 \mathrm{~Hz})$ in the occipital cortex, beta-band oscillations $(13-20 \mathrm{~Hz})$ in the parietal cortex, and fast beta-/gamma-band oscillations $(21-50 \mathrm{~Hz})$ in the frontal cortex [48]. Brain regions were also oscillating at their natural frequencies when indirectly stimulated by TMS, through brain connections. More recently, it has been shown that cortical excitability increases with time awake [49]. Short-term memory tasks have also been shown to increase the overall strength and the spatial spread of the electrical currents induced by TMS [50]. Finally, intensive training on a working memory task increases effective connectivity across frontoparietal and parieto-occipital networks [51].

\subsection{TMS-EEG in patients recovering from coma}

TMS-EEG offers an effective way to assess brain functions at rest in patients with disorders of consciousness because it does not depend on the integrity of sensory and motor pathways, it bypasses subcortical and thalamic gates, and it does not require language comprehension, nor active participation of subjects [41,52]. We recorded TMS-evoked brain responses in 17 awake patients diagnosed in UWS, MCS and LIS. When stimulating frontal and parietal brain areas of UWS patients, TMS triggered a large low-frequency wave associated with strong initial cortical activation, which did not propagate to adjacent brain areas, and dissipated rapidly. This stereotyped and local slow wave response indicates a breakdown of effective connectivity [53]. By contrast, in MCS patients, TMS triggered a series of lower amplitude and highfrequency waves associated with cortical activations that sequentially involved distant cortical areas ipsi- and contralateral to the site of stimulation. These complex long-lasting widespread activation patterns were similar to the ones recorded (Fig. 3) [52]. 
A.

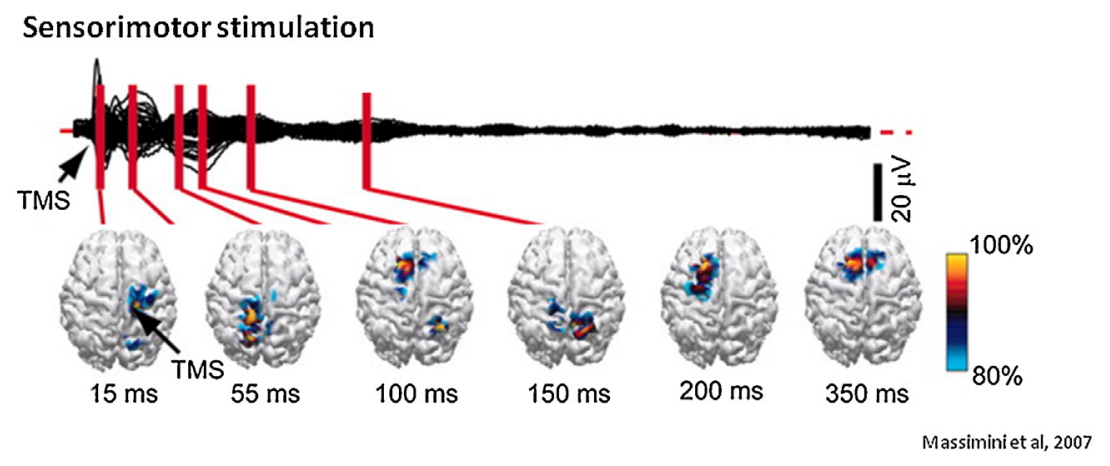

B.
Occipital stimulation
Parietal stimulation
Frontal stimulation
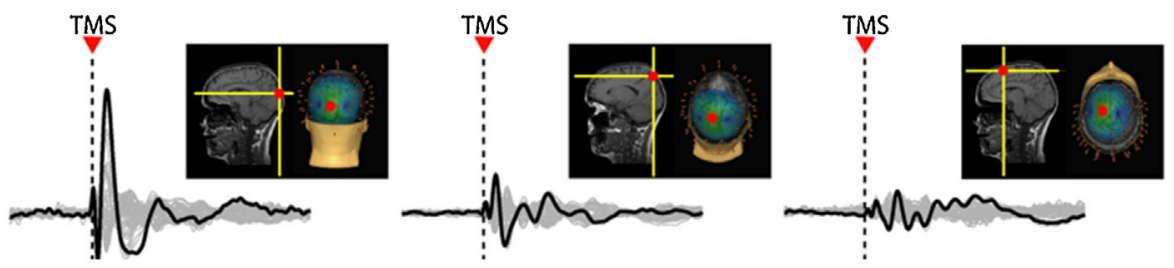

辛

Rosanova et al, 2009

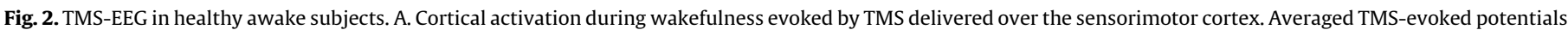

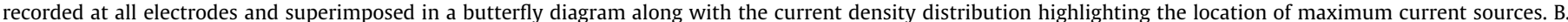

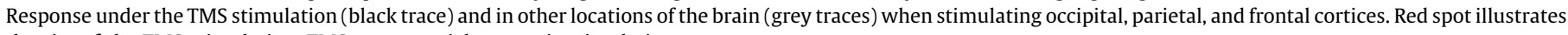
the site of the TMS stimulation. TMS: transcranial magnetic stimulation.

Adapted from [47] and [48].

Through longitudinal measurements, we measured brain activity during recovery of consciousness. When patients were in UWS, a simple local slow wave response to TMS was recorded and when patients recovered consciousness and functional communication, intracortical connectivity resurged [52]. Interestingly, one MCS patient was unresponsive at the bedside the day of the experiment but still showed complex and widespread brain responses to TMS. This suggests clear-cut differences in intracortical effective connectivity that occur at an early stage during recovery of consciousness, before reliable communication can be observed at the bedside.

Based on these results, TMS-EEG seems to constitute a novel and interesting tool to detect subtle discrimination between UWS and MCS at the single-subject level, as well as to track recovery of consciousness in severely brain-injured patients. One should, however, make sure to assess the patient in an awake state (i.e., eyes open), be aware of the potential risk of inducing epilepsy in this already fragile population, and to stimulate preserved brain

\section{Unresponsive wakefulness syndrome}

\section{Minimally conscious state}
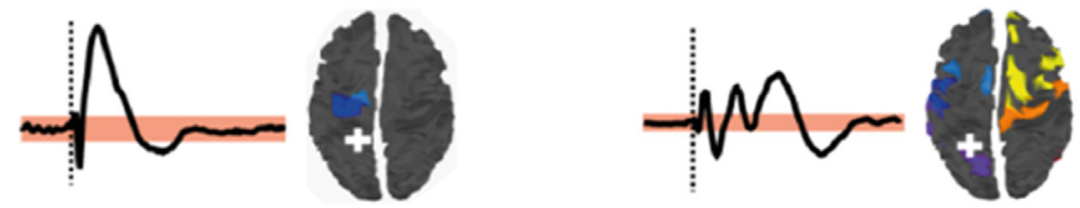

\section{Locked-in syndrome}
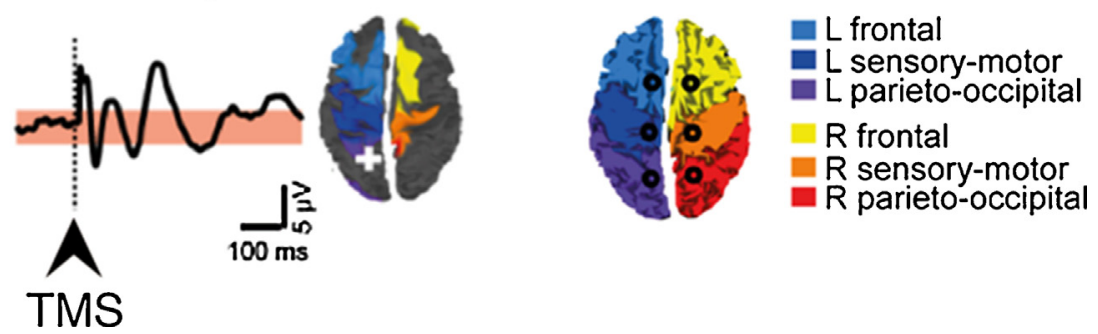

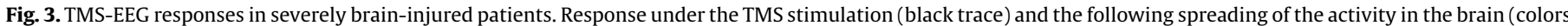

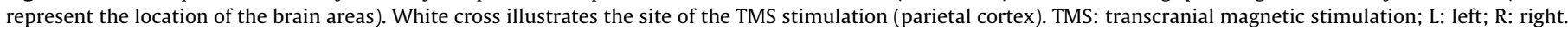
Adapted from [52]. 
areas using a neuronavigation system since TMS applied on a brain lesion might induce no response.

Another study recently confirmed the ability of the TMS-EEG to differentiate UWS from MCS patients and showed the superiority of the TMS-EEG compared to traditional neurophysiological methods, such as short-latency somatosensory evoked potential and event-related potentials [54]. In the most recent study, brain responses were compared between conscious patients with mild brain injury and healthy awake subjects [55]. Results showed altered brain reactivity and connectivity in the former compared to the latter that may be related to compensatory mechanisms of recovery. Larger population studies are needed to confirm these results and to better understand the neural mechanisms underlying the functional recovery in post-comatose patients.

\subsection{TMS-EEG in sleep and anesthesia}

The dynamics of TMS-EEG responses have also been studied under physiological and pharmacological unconscious states. During non-rapid eye movement sleep, TMS triggers a simple positive-negative slow wave, similar to the one observed in UWS patients [46]. Depending on the intensity of the stimulation, this slow wave can either remain local or burst into an explosive and stereotypical response. During deep sleep, the thalamo-cortical system despite being active and reactive thus tends to break down into isolated modules, and to lose the ability to produce differentiated responses [47]. TMS-EEG responses have also been recorded during rapid eye movement (REM) sleep during which there are dreams. In this paradoxical state, cortical responses to TMS propagate beyond the stimulation site and lasts longer than during deep sleep (although still less than during wakefulness), indicating that effective cortical connectivity is largely preserved (Fig. 4) [56].

Finally, TMS-EEG has been employed during general anesthesia induced by a pharmacological agent, benzodiazepine midazolam [57]. Results showed that responsiveness of a cortical area to TMS was maintained or even augmented, but the spread of activity to adjacent areas and the reverberatory reactivation of the stimulated site were quenched. Similarly in many regards to what occurs in UWS patients and in deep sleep, midazolam anesthesia induces a local slow wave response and a breakdown of long-range brain connectivity in response to TMS.

\section{Potential mechanisms explaining (the loss of) consciousness}

As we have seen above, consciousness involves many different cortical areas engaging in rapid causal interactions, whilst unconsciousness is characterized by stereotypical positive-negative slow wave and decreased large-scale brain connectivity. One common hypothetical neurophysiological mechanism explaining unconsciousness is bistability, which could unable cortical neurons to sustain balanced patterns of activation. The results would lead to a silent, hyperpolarized downstate after the initial activation, which could prevent the brain from successfully integrating information [58]. Potential causes of this bistability might be alterations in the balance between excitation and inhibition, increased potassium currents, and cortical deafferentation [58]. Consciousness thus seems to emerge from both functional integration (i.e., connectivity) and preserved information capacity in the brain (i.e., differentiation responses between brain regions) $[59,60]$. To achieve a most accurate estimation of the level of consciousness, theoretical approaches such as the Integrated Information Theory of Consciousness (IITC) aim at describing the mechanisms involved in consciousness [60,61]. The IITC theory emphasizes the dynamical complexity of consciousness, characterized by information being simultaneously integrated and differentiated, whereas unconsciousness results from the loss of the brain's ability to integrate information. These statements are in line with our TMS-EEG observations. Moreover, we recently designed a reliable theoretically-based measure of consciousness, the so-called Perturbational Complexity Index (PCI), in order to quantify in one number the TMS-EEG responses observed in the aforementioned physiological, pathological and pharmacological states.

\section{The Perturbational Complexity Index}

The $\mathrm{PCI}$ is a recent measure that allows estimating brain complexity, including both the information content and the integration of brain activations, through algorithmic compressibility ("zipping") [62]. This index has been shown to successfully differentiate between consciousness and unconsciousness at the individual subject level. Indeed, the PCI is invariably high in healthy awake subjects, in patients in MCS, EMCS and LIS as well as in healthy subjects in REM sleep (i.e., above 0.3 ). In contrast, the PCI is always low during deep sleep, in both UWS patients and in those under general anesthesia using midazolam, propofol or xenon (i.e., below 0.3) (Fig. 5). Further confirmation studies should test the PCI on a larger cohort of patients to objectively and quantitatively assess the level of consciousness, but also to determine the efficacy of pharmacological drugs or brain stimulation procedures in patients with disorders of consciousness.

\section{Wakefulness}

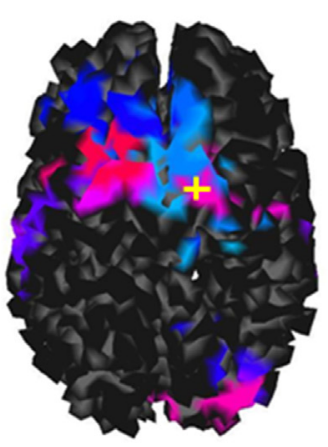

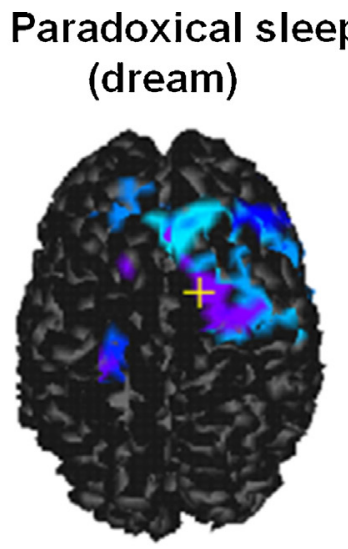

Deep sleep

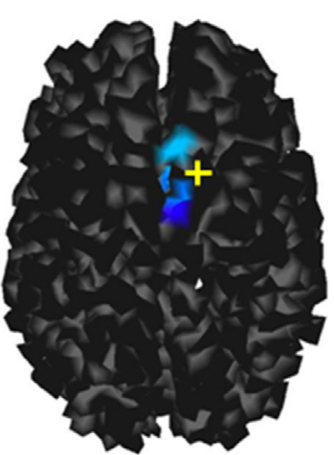

Fig. 4. TMS-EEG responses in sleep as compared to wakefulness. Yellow cross illustrates the site of the TMS stimulation (frontal cortex). Taken from [56]. 


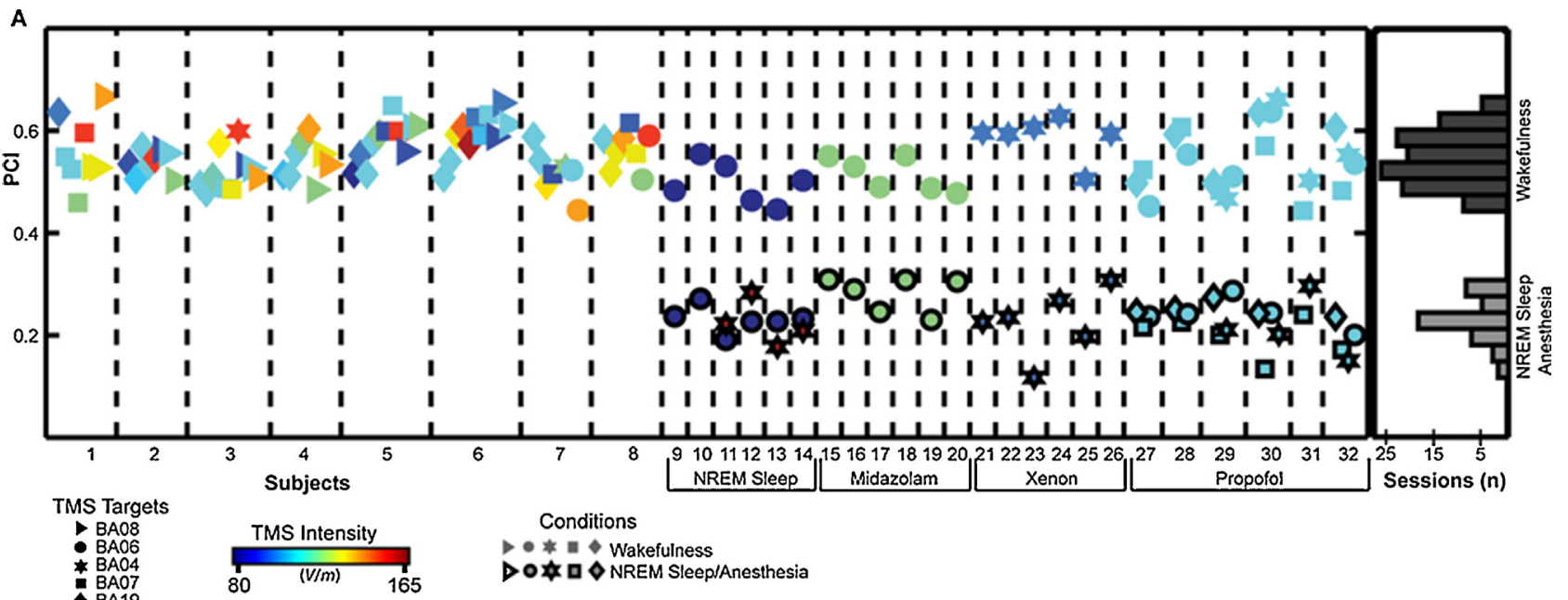

B

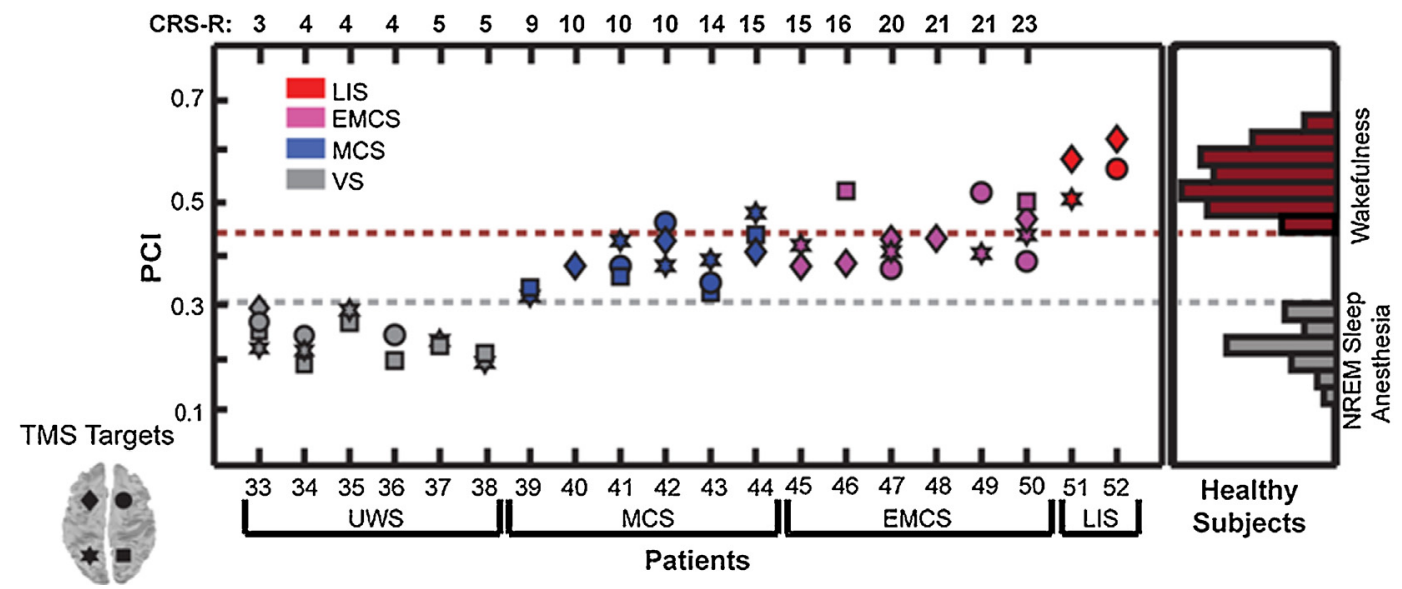

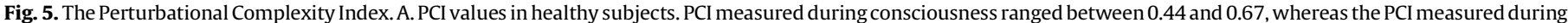

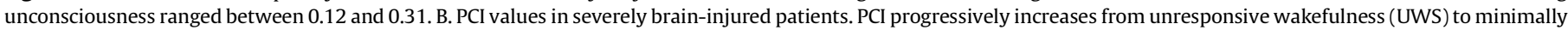
conscious (MCS) and to recovery of functional communication (EMCS). PCI attains levels of healthy awake subjects in LIS patients. CRS-R: Coma Recovery Scale-Revised.

\section{Conclusion}

Patients with disorders of consciousness constitute a major challenge regarding diagnosis, prognosis and treatment. As clinical assessment frequently leads to diagnostic errors, other techniques are needed. TMS-EEG and PCI seem to constitute an appropriate measure to assess the presence or the absence of consciousness. During consciousness, the brain is able to sustain long-range, complex patterns of activation and the PCI is high, while during unconsciousness, this ability is lost and the PCI is low. The PCI thus potentially provides a simple and reliable metric to objectively measure the level of consciousness at the singlesubject level. Future studies on a larger cohort of patients should be conducted to confirm these inaugural results. More work is also needed before using this tool in routine clinical practice, such as developing compact TMS-EEG equipment and fast, standardized data analysis software. Repetitive TMS should also be investigated for therapeutic purposes as positive effects have been observed in a few UWS and MCS patients $[63,64]$ as well as in patients suffering from aphasia [65], depression [66], tinnitus [67] or migraine [68]. The challenge in future years will also be to combine information coming from different neuroimaging techniques available (e.g., fMRI, TMS, EEG) in order to deepen our understanding of brain (dys)functions and to improve the process of diagnosis, as well as in improving the prognosis in this challenging population.

\section{Disclosure of interest}

The authors declare that they have no conflicts of interest concerning this article.

\section{Acknowledgements}

This research was funded by the Belgian National Funds for Scientific Research (FNRS), Fonds Léon-Fredericq, the James McDonnell Foundation, the European Commission, the Mind Science Foundation, the French Speaking Community Concerted Research Action (ARC-06/11-340), the Fondation médicale ReineÉlisabeth and the University of Liège. O.G. received support from NIH grant MH095984 to Bradley R. Postle and support from G. Tononi. O.G. and M.B. are postdoctoral researcher and S.L. is research director at the FNRS.

\section{References}

[1] Plum F, Posner JB. In: Davis FA, editor. The diagnosis of stupor and coma. 3rd ed, Philadelphia: Davis; 1983.

[2] Teasdale G, Jennett B. Assessment of coma and impaired consciousness. A practical scale. Lancet 1974;2:81-4.

[3] Laureys S. Science and society: death, unconsciousness and the brain. Nat Rev Neurosci 2005;6:899-909.

[4] Vanhaudenhuyse A, Boly M, Laureys S. Vegetative state. Scholarpedia 2009;4, http://www.scholarpedia.org/article/Vegetative_state.

[5] Kretschmer E. Das apallische syndrom. Z Gesamte Neurol Psychiatr 1940;169:576-9. 
[6] Calvet J, Coll J. Meningitis of sinusoid origin with the form of coma vigil. Rev Otoneuroophtalmol 1959;31:443-5.

[7] Jennett B, Plum F. Persistent vegetative state after brain damage. A syndrome in search of a name. Lancet 1972;1:734-7.

[8] Laureys S, Celesia G, Cohadon F, Lavrijsen J, León-Carrión J, Sannita W, et al. Unresponsive wakefulness syndrome: a new name for the vegetative state or apallic syndrome. BMC Med 2010;8:68. http://dx.doi.org/10.1186/1741-7015-8-68.

[9] The Multi-Society Task Force on PVS. Medical aspects of the persistent vegetative state (1). N Engl J Med 1994:330:1499-508.

[10] Cologan V, Drouot X, Parapatics S, Delorme A, Gruber G, Moonen G, et al. Sleep in the unresponsive wakefulness syndrome and minimally conscious state. J Neurotrauma 2013:30:339-46.

[11] Landsness E, Bruno MA, Noirhomme Q, Riedner B, Gosseries O, Schnakers C et al. Electrophysiological correlates of behavioural changes in vigilance in vegetative state and minimally conscious state. Brain 2011;134:2222-32.

[12] Gosseries O, Bruno MA, Chatelle C, Vanhaudenhuyse A, Schnakers C, Soddu A, et al. Disorders of consciousness: what's in a name? Neurorehabilitation 2011;28:3-14.

[13] Thibaut A, Bruno MA, Chatelle C, Gosseries O, Vanhaudenhuyse A, Demertzi A et al. Metabolic activity in external and internal awareness networks in severely brain-damaged patients. J Rehabil Med 2012;44:487-94.

[14] Laureys S, Faymonville ME, Degueldre C, Fiore GD, Damas P, Lambermont B et al. Auditory processing in the vegetative state. Brain 2000;123:1589-601.

[15] Boly M, Faymonville M, Peigneux P Lambermont B, Damas F, Luxen A et al Cerebral processing of auditory and noxious stimuli in severely brain injured patients: differences between VS and MCS. Neuropsychol Rehabil 2005; $15: 283-9$

[16] Boly M, Garrido MI, Gosseries O, Bruno MA, Boveroux P, Schnakers C, et al. Preserved feedforward but impaired top-down processes in the vegetative state. Science 2011;332:858-62.

[17] American Congress of Rehabilitation Medicine. Recommendations for use of uniform nomenclature pertinent to patients with severe alterations of consciousness. Arch Phys Med Rehabil 1995;76:205-9.

[18] Giacino JT, Ashwal S, Childs N, Cranford R, Jennett B, Katz DI, et al. The minimally conscious state: definition and diagnostic criteria. Neurology 2002;58:349-53.

[19] Bruno MA, Vanhaudenhuyse A, Thibaut A, Moonen G, Laureys S. From unresponsive wakefulness to minimally conscious PLUS and functional locked-in syndromes: recent advances in our understanding of disorders of consciousness. J Neurol 2011;258:1373-84.

[20] Bruno MA, Majerus S, Boly M, Vanhaudenhuyse A, Schnakers C, Gosseries O, et al. Functional neuroanatomy underlying the clinical subcategorization of minimally conscious state patients. J Neurol 2012;259:1087-98.

[21] Laureys S, Faymonville ME, Luxen A, Lamy M, Franck G, Maquet P. Restoration of thalamocortical connectivity after recovery from persistent vegetative state. Lancet 2000;355:1790-1.

[22] Schnakers C, Majerus S, Goldman S, Boly M, Van Eeckhout P, Gay S, et al. Cognitive function in the locked-in syndrome. I Neurol 2008:255:323-30.

[23] Bauby JD. Le scaphandre et le papillon.The diving bell and the butterfly Paris: Laffont Edition; 1997, 139 p.

[24] Lule D, Noirhomme Q, Kleih SC, Chatelle C, Halder S, Demertzi A, et al. Probing command following in patients with disorders of consciousness using a braincomputer interface. Clin Neurophysiol 2013;124:101-6.

[25] Stoll J, Chatelle C, Carter O, Koch C, Laureys S, Einhauser W. Pupil responses allow communication in locked-in syndrome patients. Curr Biol 2013·23:R647-8.

[26] Bruno MA, Bernheim JL, Ledoux D, Pellas F, Demertzi A, Laureys S. A survey on self-assessed well-being in a cohort of chronic locked-in syndrome patients: happy majority, miserable minority. BMJ Open 2011;1:e000039.

[27] Schnakers C, Vanhaudenhuyse A, Giacino JT, Ventura M, Boly M, Majerus S, et al. Diagnostic accuracy of the vegetative and minimally conscious state: clinical consensus versus standardized neurobehavioral assessment. BMC Neurol 2009;9:35.

[28] Giacino JT, Kalmar K, Whyte J. The JFK coma recovery scale-revised: measurement characteristics and diagnostic utility. Arch Phys Med Rehabil 2004;85:2020-9.

[29] Seel RT, Sherer M, Whyte J, Katz DI, Giacino JT, Rosenbaum AM, et al. Assessment scales for disorders of consciousness: evidence-based recommendations for clinical practice and research. Arch Phys Med Rehabil 2010;91:1795-813.

[30] Bruno MA, Ledoux D, Lambermont B, Damas F, Schnakers C, Vanhaudenhuyse A, et al. Comparison of the Full Outline of UnResponsiveness and Glasgow Liege Scale/Glasgow Coma Scale in an intensive care unit population. Neurocrit Care 2011;15:447-53.

[31] Majerus S, Gill-Thwaites H, Andrews K, Laureys S. Behavioral evaluation of consciousness in severe brain damage. Prog Brain Res 2005:150:397-413.

[32] Faugeras F, Rohaut B, Weiss N, Bekinschtein TA, Galanaud D, Puybasset L, et al Probing consciousness with event-related potentials in the vegetative state. Neurology 2011;77:264-8.

[33] Monti MM, Vanhaudenhuyse A, Coleman MR, Boly M, Pickard JD, Tshibanda L, et al. Willful modulation of brain activity in disorders of consciousness. N Engl J Med 2010;362:579-89.

[34] Cruse D, Chennu S, Chatelle C, Bekinschtein TA, Fernandez-Espejo D, Pickard $\mathrm{JD}$, et al. Bedside detection of awareness in the vegetative state: a cohort study. Lancet 2011;378:2088-94.

[35] Naci L, Owen AM. Making every word count for nonresponsive patients. JAMA Neurol 2013. http://dx.doi.org/10.1001/jamaneurol.2013.3686 [Epub ahead of print].

[36] Vogel D, Markl A, Yu T, Kotchoubey B, Lang S, Muller F. Can mental imagery functional magnetic resonance imaging predict recovery in patients with disorders of consciousness? Arch Phys Med Rehabil 2013:94:1891-8.

[37] Gosseries O, Zasler N, Laureys O. Recent advances in disorders of consciousness: focus on the diagnosis. Brain Inj [in press].

[38] Hallett M. Transcranial magnetic stimulation and the human brain. Nature 2000;406:147-50.

[39] Lapitskaya N, Coleman M, Nielsen J, Gosseries O, de Noordhout A. Disorders of consciousness: further pathophysiological insights using motor cortex transcranial magnetic stimulation. Prog Brain Res 2009:177:191-200.

[40] Miniussi C, Rossini PM. Transcranial magnetic stimulation in cognitive rehabilitation. Neuropsychol Rehabil 2011;21:579-601.

[41] Massimini M, Boly M, Casali A, Rosanova M, Tononi G. A perturbational approach for evaluating the brain's capacity for consciousness. Prog Brain Res 2009;177:201-14

[42] Rosanova M, Casarotto S, Pigorini A, Canali P, Casali AG, Massimini M. Combining transcranial magnetic stimulation with electroencephalography to study human cortical excitability and effective connectivity. In: Fellin THM, editor. Neuronal network analysis, Neuromethods. Volume 67, Humana Press, Springer Science+Business, LLC. p. 435-457.

[43] Casarotto S, Romero Lauro LJ, Bellina V, Casali AG, Rosanova M, Pigorini A, et al. EEG responses to TMS are sensitive to changes in the perturbation parameters and repeatable over time. PLoS One 2010;5:e10281.

[44] Rogasch NC, Fitzgerald PB. Assessing cortical network properties using TMSEEG. Hum Brain Mapp 2012.

[45] Casali AG, Casarotto S, Rosanova M, Mariotti M, Massimini M. General indices to characterize the electrical response of the cerebral cortex to TMS. Neuroimage 2010;49:1459-68.

[46] Massimini M, Ferrarelli F, Huber R, Esser SK, Singh H, Tononi G. Breakdown of cortical effective connectivity during sleep. Science 2005;309:2228-32.

[47] Massimini M, Ferrarelli F, Esser SK, Riedner BA, Huber R, Murphy M, et al. Triggering sleep slow waves by transcranial magnetic stimulation. Proc Natl Acad Sci U S A 2007;104:8496-501.

[48] Rosanova M, Casali A, Bellina V, Resta F, Mariotti M, Massimini M. Natural frequencies of human corticothalamic circuits. J Neurosci 2009;29:7679-85.

[49] Huber R, Maki H, Rosanova M, Casarotto S, Canali P, Casali A, et al. Human cortical excitability increases with time awake. Cereb Cortex 2013;23:332-8.

[50] Johnson J, Kundu B, Casali A. Postle B. Task-dependent changes in cortical excitability and effective connectivity: a combined TMS-EEG study. J Neurophysiol 2012;107:2383-92

[51] Kundu B, Sutterer DW, Emrich SM, Postle BR. Strengthened effective connectivity underlies transfer of working memory training to tests of short-term memory and attention. J Neurosci 2013;33:8705-15.

[52] Rosanova M, Gosseries O, Casarotto S, Boly M, Casali A, Bruno M, et al. Recovery of cortical effective connectivity and recovery of consciousness in vegetative patients. Brain 2012;135(Pt 4):1308-20.

[53] Friston KJ. Functional and effective connectivity: a review. Brain Connect 2011:1:13-36

[54] Ragazzoni A, Pirulli C, Veniero D, Feurra M, Cincotta M, Giovannelli F, et al. Vegetative versus minimally conscious states: a study using TMS-EEG, sensory and event-related potentials. PLoS One 2013;8:e57069.

[55] Tallus J, Lioumis P, Hämäläinen H, Kähkönen S, Tenovuo O. TMS-EEG responses in recovered and symptomatic mild traumatic brain injury. J Neurotrauma 2013;30:1270-7

[56] Massimini M, Ferrarelli F, Murphy M, Huber R, Riedner B, Casarotto S, et al. Cortical reactivity and effective connectivity during REM sleep in humans. Cogn Neurosci 2010;1:176-83.

[57] Ferrarelli F, Massimini M, Sarasso S, Casali A, Riedner BA, Angelini G, et al. Breakdown in cortical effective connectivity during midazolam-induced loss of consciousness. Proc Natl Acad Sci U S A 2010;107:2681-6.

[58] Massimini M, Ferrarelli F, Sarasso S, Tononi G. Cortical mechanisms of loss of consciousness: insight from TMS/EEG studies. Arch Ital Biol 2012:150:44-55.

[59] Boly M, Massimini M, Tononi G. Theoretical approaches to the diagnosis of altered states of consciousness. Prog Brain Res 2009;177:383-98.

[60] Tononi G. Consciousness as integrated information: a provisional manifesto. Biol Bull 2008:215:216-42.

[61] Tononi G. Integrated information theory of consciousness: an updated account. Arch Ital Biol 2012;150:56-90.

[62] Casali AG, Gosseries O, Rosanova M, Boly M, Sarasso S, Casali KR, et al. A theoretically based index of consciousness independent of sensory processing and behavior. Sci Transl Med 2013;5:198ra05.

[63] Louise-Bender Pape T, Rosenow J, Lewis G, Ahmed G, Walker M, Guernon A, et al. Repetitive transcranial magnetic stimulation-associated neurobehavioral gains during coma recovery. Brain Stimul 2009;2:22-35.

[64] Manganotti P, Formaggio E, Storti SF, Fiaschi A, Battistin L, Tonin P, et al. Effect of high-frequency repetitive transcranial magnetic stimulation on brain excitability in severely brain-injured patients in minimally conscious or vegetative state. Brain Stimul 2013;6:913-21.

[65] Dammekens E, Vanneste S, Ost J, De Ridder D. Neural correlates of high frequency repetitive transcranial magnetic stimulation improvement in post-stroke non-fluent aphasia: a case study. Neurocase 2014;20:1-9.

[66] Dumas R, Padovani R, Richieri R, Lançon C. Repetitive transcranial magnetic stimulation in major depression: response factor. Encephale 2012:38:360-8.

[67] De Ridder D, Song J, Vanneste S. Frontal cortex TMS for tinnitus. Brain Stimul 2014;20:1-9.

[68] Lipton R, Pearlman S. Transcranial magnetic stimulation in the treatment of migraine. Neurotherapeutics 2010;7:204-12. 